\title{
Design expertise in public and social innovation
}

\author{
VAN DER BIJL-BROUWER Mieke ${ }^{\mathrm{a}}$ and MALCOLM Bridget ${ }^{\mathrm{a}^{*}}$ \\ a University of Technology Sydney \\ * mieke.vanderbijl-brouwer@uts.edu.au \\ doi: $10.21606 /$ dma.2017.483
}

\begin{abstract}
Over the past decade a new type of design practice has emerged that is aimed at addressing complex societal problems through public and social sector innovation. As opposed to traditional product design teams, design processes in this sector tend to be distributed among numerous actors. In these 'designing networks' it is less clear which type and level of design expertise is required and who should have it. In this paper, we investigate design expertise in public and social innovation through a study of the practices of five innovation agencies. We particularly looked at the expertise of framing. The study provides preliminary answers to how much and what kind of design expertise we need, who should have it, and how we can teach and learn this expertise. The results indicate that designing for complex societal problems requires high level design expertise with regard to framing and managing a design process. This requires capability building beyond the methodical approaches that are currently being offered to public and social sector staff members.
\end{abstract}

social innovation; design expertise; framing; capability building

\section{Introduction}

Over the past decade, design has emerged as a useful approach in dealing with the complex societal issues that the world is facing. Dorst (2015) advocates that the new open, complex, dynamic and networked problems of our time require a radically different response, and that expert designers have developed unique approaches to address these new types of problems. Bason (2010) argues that these design approaches and tools can help government to consciously create meaning and value they want citizens, businesses and other actors in society to experience. At the same time many argue that societal problems require interventions beyond what the public and social sector can offer, such as initiatives designed by grassroots organisations (Manzini, 2015).

These theoretical arguments for public and social innovation through design are also reflected in practice. A new practice is emerging in which design approaches are used to design and implement public and social services, products, policies and procedures across domains such as housing, employment, health, crime prevention, and education. At the core of this practice are the new practitioners: pioneers who are experimenting with methods and practices of public and social

1. This work is licensed under a Creative Commons Attribution-NonCommercial-Share Alike 4.0 International License.

2. https://creativecommons.org/licenses/by-nc-sa/4.0/ 
sector innovation and who are often working from innovation agencies or 'labs' inside or alongside public and social sector organisations. Irrespective of their position in relation to public, or social sector organisations, these labs share the aim of generating value for society.

There is an interesting difference between the way that people collaborate in traditional design teams and the way that they collaborate in these new social innovation contexts. In traditional design teams in the product manufacturing industry, there are clear boundaries between the team and the external world. The external voices of the consumer, user, and client are included in the design process through distinct roles in the design team such as the marketing manager, user experience expert, and project leader (see for example van der Bijl-Brouwer \& van der Voort, 2014). These external stakeholders might also be invited to be actively involved in participatory design processes. However, the design decisions are made within the confines of the design team's office and it is clear from the start of the project that the client or owner of the design team will implement the solution. In comparison, in public and social sector innovation labs these boundaries between the design team and the external world are much less clear. External stakeholders are often not just participants in a co-design process but are an active part of the design team. Moreover, it is often not clear at the beginning of the design project who will be implementing the result of the design process.

Manzini $(2015, \mathrm{p} 38)$ refers to these connected types of design teams as 'designing networks': "in a connected world, design processes tend to be increasingly distributed among numerous actors who differ in culture, motivation and professional development". While the design research field has developed a basic understanding of the type of expertise that is required for traditional product design teams over the past decades (Cross, 2004; Lawson \& Dorst, 2009; Valkenburg \& Dorst, 1998), it is less clear what type and what level of design expertise is required in designing networks that are aimed at addressing complex societal problems. This includes which stakeholders need to have design expertise, how much design expertise they should have, and how this expertise should be taught and learned. In this paper, we investigate this topic through a study that was aimed at understanding the design practices of five public and social sector innovation labs around the world. We will explore what role design expertise and capability building plays in these design networks that are aimed at creating social and public value.

\subsection{Design practices and expertise}

As the practice of design in the context of public and social sector innovation matures, the research into this area is only just beginning to emerge. A series of case studies by the UK Design Council (2013), on design for public sector innovation of the Sharing Experiences Europe (SEE) network, showed that design contributes to public sector innovation in many different ways. This includes looking at the entire system to redefine the problem from the ground up; understanding user needs; testing iteratively to prevent expensive and risky pilots; integrating the process of problem analysis, solution development and implementation; and engaging teams and departments in collaboration across silos. Yee and White (2015) studied the conditions for design to achieve the desired impact in the context of public and third sector projects, through an analysis of case studies of service innovation projects. They found that community building was the most important condition for design to have the greatest impact in innovation and transformation projects, followed by leadership and building the capacity and skills across the organisation. In this paper we further investigate the theme of capacity building to develop design expertise in the public and social sector.

At the most basic level, design can be described by using Simon's definition of 'changing existing situations into preferred ones' (Simon, 1996). But what are the skills that we need to achieve that? Yee and White mention design skills specifically in public and social sector organisations and focus on the concepts of 'mind set' as well as 'practical skills' to apply tools including user-research and generative design methods. The focus on 'mind set' and 'application of tools' seems to be a common understanding of design in the public and social sector innovation context (also described by Nelson and Stolterman 2012). Although these are important elements required to design, we believe that 
the notion of 'design expertise' is missing from the context of public and social sector innovation. Nelson and Stolterman (2012, p225) describe design expertise as the "unfolding process of moving from novice to expert" which is consistent with the understanding in design research and pedagogy. Many scholars have studied the expertise of designers such as architects and product designers to understand how this can be taught.

Lawson and Dorst (2009) conclude that expert designers undertake five main activities: managing, formulating, moving, evaluating, and representing. The activity of 'formulating', the ability to reformulate and organise ill-structured or wicked problems, is of particular interest as it is one of the most important and unique skills of designers. The specific approach of designers to reformulate problems is called 'framing'.

\subsubsection{Framing}

Dorst (2011) argues that the creation of new frames is at the core of how designers think. The notion of framing stems from the work of Schön (1983). He stated: "in real world practice, problems do not present themselves to the practitioner as givens. In order to convert a problematic situation to a problem, a practitioner needs to do a certain kind of work. [..] Problem setting is a process in which interactively we name the things to which we will attend and frame the context in which we will attend to them" (p40). A particularly interesting aspect of framing by expert designers is the way that frames are used as a strategy to 'problem-solve'. This has been shown most clearly by Dorst and Cross (2001) through an in-depth study of the practices of expert designers which validates a model of 'co-evolution'. This model shows that framing is about the co-evolution of a problem alongside a solution. "It seems that creative design is not a matter of first fixing the problem, and then searching for a satisfactory solution concept. Creative design seems more to be a matter of developing and refining together both the formulation of a problem and ideas for a solution, with constant iteration of analysis, synthesis and evaluation processes between the two notional design 'spaces'-problem space and solution space" (p434).

\subsubsection{Levels of expertise}

When talking about 'design expertise' for this study, it is relevant to consider the level of expertise that is required in public and social sector innovation. In his book 'Design, when everybody designs' Manzini (2015) describes two ends of a scale of design expertise in the context of social innovation, diffuse and expert design. Diffuse design is the type of design knowledge that he argues is the natural designing capacity of every human being, while design experts are people trained to operate professionally as designers. Lawson and Dorst (2009) argue that design expertise is not acquired in some continuous and seamless manner but that there appear to be more or less distinct layers of expertise, which each enable quite different modes of thinking and action. The layers are based on a generic model of expertise developed by Dreyfus, and include a novice (rule-based thinking), advanced beginner (situation-based thinking), competent (strategy-based thinking), expert (intuitive thinking), master (context-based thinking) and visionary level (domain-based thinking). Lawson and Dorst include a 'beginner 'level because they acknowledge, like Manzini, that most people are already 'novice' by applying design as an 'everyday act'. What is most relevant for this study is to describe the difference between the novice level and the expert level. Novice designers use largely rule-based and convention-based thinking. They consider the objective features of a situation, as provided by the experts, and follow strict rules to deal with the problem. Rule-based thinking allows us to tackle complicated problems with approaches that are often a combination of logic and the experience of many designers before us (Lawson \& Dorst, 2009, p68). This is very different from the 'expert' level, where the expert responds to a situation intuitively, applying design judgement and intention that allows outcomes to emerge (Nelson and Stolterman 2012).

\subsubsection{Capability building}

It is widely acknowledged that building the design capability of staff within the public and social sector can lead to more 'transformative change' that allows the sector to respond to challenges in 
new ways (van der Bijl-Brouwer, Kaldor, Watson \& Hillen, 2015; Mulgan, 2014; Yee \& White, 2015). In the remainder of this paper we will further investigate design expertise and capability building in the social and public sector, through a study into the practice of public and social sector innovation labs.

\section{A study of public and social sector innovation practices}

The objective of our study was to investigate the practices of public and social sector innovation agencies that were addressing complex societal problems. We were particularly interested in the 'designerly elements' of the practice with regard to framing, human-centred design (HCD), and collaboration. In this paper we will focus on the framing practices. The theme of 'capability building' emerged during the study and was further explored in data analysis.

\subsection{Research method}

The study was conducted using a retrospective case-study approach (Yin, 2009). We invited five international public and/or social sector innovation agencies to participate, and selected an appropriate case study within each of the agencies. The selection criteria included that the project should be aimed at addressing a complex societal issue, included collaboration with a public or social sector partner, and was executed by a team with at least five years of experience working in the public or social innovation sector. The research method included document analysis of the reports and design documentation, and interviews with the team members from the innovation lab, as well as their main partners in the public or social sector. We conducted 16 interviews in total. All interviews were transcribed, and relevant sections were coded and explored through an inductive thematic analysis. To investigate the framing practices within the case studies, we mapped out how 'solutions' and frames or problem definitions were developed over the course of each project.

Please note that the limitations of this case-study approach are that results cannot be generalised to the practices of the agencies as a whole. Furthermore, it does not reveal the level of detail in the framing process that would be available from a protocol analysis. A generally cited limitation of case study analysis is its small sample size with regard to generalisation to a larger population (Yin, 2009).

\subsection{Five case studies}

Each case study was focussed on addressing a complex societal problem and involved initial collaboration with a key funder or partner in the social or public sector. In all case studies this collaboration was then expanded to a much broader group of stakeholders. The five case studies are described in Table 1. The agencies each have a different position in relation to government. Figure 1 demonstrates the role each agency had in relation to government within a model developed by Bason and Schneider (2014). 
Table 1: overview of the five case studies

\begin{tabular}{|l|l|l|l|}
\hline Agency & Case Study domain & Country & Outcome \\
\hline MindLab & Primary Education & Denmark & $\begin{array}{l}\text { Several initiatives of which one, the 'Speed } \\
\text { sharing event' was successfully } \\
\text { implemented }\end{array}$ \\
\hline KennisLand (KL) & Disadvantaged Youth & $\begin{array}{l}\text { The } \\
\text { Netherlands }\end{array}$ & $\begin{array}{l}\text { Seven different prototypes of which some } \\
\text { are being developed further }\end{array}$ \\
\hline InWithForward (IWF) & Disability sector & Canada & $\begin{array}{l}\text { Several initiatives of which 'Kudoz' and } \\
\text { 'FifthSpace' were successfully } \\
\text { implemented }\end{array}$ \\
\hline $\begin{array}{l}\text { The Australian } \\
\text { Innovatre for Social }\end{array}$ & $\begin{array}{l}\text { Disadvantaged } \\
\text { Families }\end{array}$ & Australia & $\begin{array}{l}\text { Three prototypes and a 'prospectus' which } \\
\text { are currently being tested }\end{array}$ \\
\hline $\begin{array}{l}\text { CoLab } \\
\text { ITACSI }\end{array}$ & $\begin{array}{l}\text { General Public } \\
\text { Services }\end{array}$ & Canada & $\begin{array}{l}\text { Input for the development of an 'Open } \\
\text { Government' strategy }\end{array}$ \\
\hline
\end{tabular}

owner | funder | co-funder | partner | client | endorser

\begin{tabular}{rrr} 
GOV-LED & \multicolumn{2}{c}{ GOV-ENABLED } \\
\multicolumn{1}{r}{$\begin{array}{c}\text { MindLab } \\
\text { (Copenhagen) }\end{array}$} & TACSI & Kennisland \\
(NSW) & (Amsterdam) \\
Co-Lab & InWithForward \\
(Alberta) & (Vancouver)
\end{tabular}

Figure 1: position of each case study in relation to government

The 'design networks' in each of the case studies consisted of the agencies in addition to a broader group of stakeholders. The leading teams from the agencies each had between two and four members. In four of the five case studies at least one member from the funding or partnering organisation had an active role in the design process. Service providers and/or public servants or managers were actively involved in the design process in each of the case studies through participatory design or through being an active member of the design team, taking part in design and research activities, and decision-making. In all case studies except CoLab, end-users or citizens were actively involved through participatory design or being an active member of the design team.

\section{Results: design expertise and framing}

It is clear that framing was a key element of the design expertise throughout all five case studies. All groups spent considerable time framing the problem, although different principles and approaches were used to develop and evolve these frames.

\subsection{Framing principles}

Two principles in terms of how the problems were framed could be distinguished in all the case studies: 'opening up the brief' and 'systemic thinking'. 


\subsubsection{Opening up the brief}

All case studies started with a briefing process, in which the agencies and their partnering or funding organisations negotiated the initial brief. In this process, all agencies 'opened up' the brief to allow for a broader framing and/or a more positive view on the problem.

[CEO, TACSI]: "So we started off with a brief. [..] And then from there, we really started, I guess, pounding the pavement and seeking to really test, unpack all of the assumptions that were sitting behind the framing questions. And I think what we learnt very, very, very quickly was some fundamental things that opened up the brief to a whole new level.[..]"

[Team member, KL]: "it is also about deproblematising of what first is seen as a problem."

This opening up of the brief was often done through broadening the framing from being just about the perspective of the client, to being about what is required for society.

[Team member, KL]: "We sometimes realise that a point of inquiry is set because we have a client [...] who defines the problem from the perspective of their organisation or system, what might not be the question that would be posed by society."

\subsubsection{Systemic thinking}

Three of the five studies framed the problem explicitly on two different levels: a strategic systems level focused on the broader system in which the problem sits, and a service level that was aimed at addressing specific problems for the target group. For example, TACSI developed service prototypes to address problems for families in the short term, as well as a 'prospectus' of the big picture systems changes that were required to generate larger scale changes. KL developed specific interventions that were directly targeted at helping youth, as well as prototypes on how to develop policy. TACSI refers to this process as 'two-track thinking':

[CEO, TACSI]: "So I guess we've got these two tracks now. We've got these prototypes that our family members can go, "Oh look, we're doing these things" that are tangible and alongside that, we've got this prospectus that we've created that we're just working with another set of funders around now, to look at well how do we actually start to conceptualise what a different system or different parts of the system could look like."

The strategic systems level is aimed at developing solutions that allow the system to adapt and evolve, beyond just the target group in the specific case study. This is in line with what Nelson and Stolterman $(2012$, p57) call the 'systemic nature' of design expertise, which focuses our full attention on the connections and relations between people, subjects, objects, and ideas - rather than just the things themselves. The other two remaining case studies also clearly included this focus on broader relationships in how they framed the problem.

\subsection{Input for the development of frames}

In the process of developing frames, the groups used different types of 'input'. All approaches were human-centred, but the way this was integrated in the design process differed significantly between the case studies.

\subsubsection{Framing using qualitative human-centred research}

All case studies adopted a human-centred approach, using different types of resources to understand the needs and aspirations of end-users and other stakeholders. Methods included for example the collection of stories from different stakeholders, deep or rapid ethnography, social theories, light institutional immersion and co-design.

The time spent on gathering insights into end-users' or stakeholders' needs, aspirations and perspectives differed significantly between the five case studies. In three cases there was a very rigorous 'research' stage, involving elaborate field research based on long ethnographic studies 
and/or many stakeholder interviews, and a rigorous data-analysis stage to identify themes in the data.

[Team member, IWF]: "We don't do one-day interviews, we're really committed to immerse ourselves in the ethnographic work. We build these great relationships... we were committed to this."

In the other two case studies, human-centred research was applied in a more pragmatic way where research into stakeholders needs, aspirations, and perspectives was conducted at those stages when it was considered most useful and relevant in the design process (this is referred to in the next section).

\subsubsection{Working with assumptions}

In three case studies the participants clearly showed how they started with assumptions for an initial framing of the problem, rather than doing research first to frame the problem. Research was then used to confirm or open up the frame. For example:

[Team member, TACSI]: "TACSI has a testing assumptions model - we start in the office and we frame our assumptions and we name our assumptions and then we go out of the office and we test our assumptions. So we tried to model that kind of on a weekly basis."

In all the cases, the research is not just used to 'confirm' assumptions, but to open up the process and lead to new frames and ideas. This was most clearly explained by MindLab:

[Team member, MindLab]: "We engaged directly with the teachers so they could also come up with new ideas on how to come closer to this desired future state... we made these future scenarios with props like paper figures and [context pictures], because that kind of sets a tone, [makes it concrete] and it gives people a direction. But it still leaves, [..] an openness for them to come up with ideas that [we] hadn't come up with ourselves. So this is also a crucial part of what we do. Giving people direction, but at the same time, maintaining an openness to exploration."

But if the framing is not 'driven' by human-centred research, then how did the teams generate their initial framing? Two of the case studies had explicit strategies to achieve this. To generate the initial framing, CoLab used specific systemic design methods and tools, including systems mapping, risk mapping, affinity mapping, brainstorming and role-playing the user's perspective etc. MindLab adopted a more solution-focused strategy, using provocative prototypes to provoke stakeholders thinking about what they might need. The prototypes were developed by the MindLab team using desired future-state thinking, and using metaphors to generate ideas.

[Team member, MindLab]: [we asked ourselves:] "what is the desired outcome?" and we thought about what other tools that are useable in this context, and then we had a brain storm about it from other businesses, what are some of the solutions that we maybe could take some inspiration from."

\subsection{Evolution of framing}

All cases showed a divergence and evolution of the framing of the problem and the development of solutions. For example, the IWF case study started with a problem frame of 'how do we reduce social isolation amongst adults living with cognitive disabilities', to a focus on 'isolation from learning and purpose', to 'how can we help people with identifying interest for employment opportunities'. What is interesting is the way that the case studies differed with regard to the relationship between human-centred research and framing, the way that framing is 'planned for' and the co-evolution of problem and solution.

\subsubsection{Linearity of human-centred research and framing}

The case studies that used elaborate human-centred research approaches as input to their framing, differed with regard to the 'linearity' of that process. In one case study, there was a linear approach 
in which the research preceded the framing and the generation of solutions. In other cases, the research was used to let the framing evolve. This can be illustrated through how IWF used social theories. Rather than first finding social theories and then using that to frame the problem, they included the theories in a more iterative way:

[Team member, IWF]: "So one thing that we did during the ethnographic research part is that we used quite a few different articles but without like specifically choosing for one or another. There was a stage where we just took what we thought resonated or was inspiring and then we tried it out in a design research tool and then we were trying like does this make sense, is it something that helps our understanding of this population group or not."

[Team member, IWF]: "Later on when we started prototyping, it was like at least half year later, we came across other social theories that would then actually be really useful in shaping what it was that we were doing and one of those theories was social cognitive career theory."

This is a more strategic application of HCD in which it is not just used to 'respond' to a problem that has come up in the research, but rather is used strategically in the evolution of the problem frame (van der Bijl-Brouwer \& Dorst, 2017).

\subsubsection{Co-evolution of problem and solution}

As described in the introduction, design expertise is characterised by a co-evolution of problem and solution. This was very clear in the MindLab case in which the team used a solution-focused approach to explore the problem, although they explain that other approaches are also used in their agency:

[Team member, MindLab]: "we agreed [..] to go out and prototype things fast and learn about the present via provocations about the future. But we also have colleagues who are more keen on [..] making more thorough research, really trying to understand what is the issue at hand here before they go about doing more prototype'ish sort of things. So both approaches kind of live side by side here anyway."

IWF also showed a very clear co-evolution of problem and solution, through continuous iterative prototyping loops which are not just about how to improve the solution, but also about how to frame the problem. In two of the case studies it is unclear how the problem and solution co-evolved because the agencies were either not involved or not yet in the prototyping stage.

One case study clearly showed no explicit co-evolution of problem and solution. In that case study the step from problem exploration to solution was made in one session, using a methodical approach including templates or 'canvasses' to move from themes to ideas, without an explicit way to refer back to the problem framing. This led to some expressions of discomfort from participants (referred to in the next section).

\subsection{Planning and managing the design process}

Another important theme that emerged was the extent to which the design process was planned.

[Team member, MindLab]: "It's important actually to understand that we didn't have a plan from the beginning as we didn't have a set plan how it would evolve."

This is in line with the 'unplanned' and intuitive nature of framing in expert design practice, as explained through a quote from a CoLab team member:

"To me reframing is something that you are looking for in design, but you are not planning for it...you don't know when that moment's going to come, but you are definitely open to looking for it." 
Lawson and Dorst (2009) refer to this activity as 'managing' - stepping out of the "flow of the design activity, and asking if the process is going well or might be steered differently" (p58). It is this unplanned and 'messy' nature of the design process that makes it uncomfortable for those stakeholders in the network who are not familiar with design, for example:

[Public servant, MindLab]: "... it was a challenge for us as well because we didn't know the outcome. Normally we know like somewhere where it's going but in this project, we had to let go and just let them decide on the way."

Interestingly, the opposite was also true. In one case study the facilitators structured the process very carefully through a method developed by the agency itself, which involved a structured number of steps with clear tools and templates to guide participants through each of the steps. The most difficult step was to go from investigating the problem space to developing solutions. A participant mentioned:

"From these themes, [the agency] facilitated a creative session to generate ideas [..]. We used a canvas for that. [..] The canvas helped us associate from themes to ideas [..] It was a kind of brainstorm session, but it all had to happen within one evening and to be honest that did not completely, I was not completely satisfied with that. I felt like we needed more to diverge and associate. [..]"

And two other participants in a separate interview had a similar response to that same process

[Participant 1]: "[..] if you would give that some more time and more rest, then it would be able to 'simmer' and now there is this 'jump in the process', and you continue and you don't look back, you close off a few pathways."

\section{[..]}

[Participant 2]: "[And] I stood there thinking, ok, well, last week we talked about this and that and thought yes, but, it's not yet. It has not evolved enough."

[Participant 1]: it has not matured enough, it's not ripe."

\section{Results: capability building}

Three of the case studies had a deliberate approach to build design or innovation capability in the network in addition to achieving project outcomes. In two of those, CoLab and KL, capability building was the priority, and the case served as an example to learn about the design or innovation approach. In the other two cases the focus was on project outcomes, not on capability building. These differences in focus are illustrated in Figure 2.

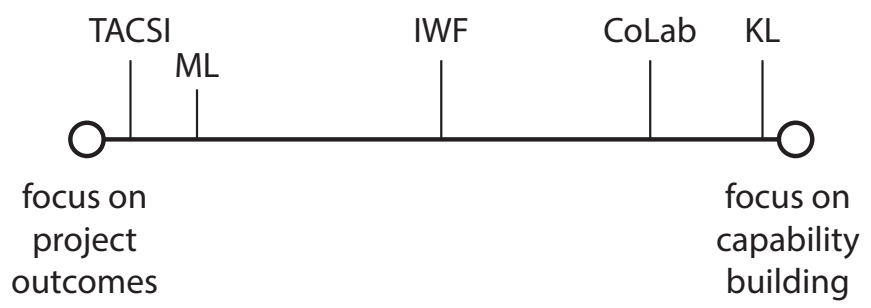

Figure 2: focus of the case studies regarding project outcomes or capability building

As capability building was not an initial focus of this research project, we have limited insight into the impact this had on participants. However, we do have some anecdotal evidence of the learning outcomes of some of the projects and how that transfers to other parts of participants' work.

In the KL case study, all interviewed participants indicated that they had learned from the process and would apply it in their work. 
[Public servant, KL]: "So in my policy about [one of my other projects], I am going to [collect qualitative user data in a similar way to this project]. So, it does have impact on how I work."

MindLab, which did not have a deliberate training approach, but did involve all stakeholders in the process through co-design, managed to impact on people's thinking.

[Public servant, MindLab]: "I have two other projects. I can feel that I changed my way of thinking because of this project. And then I have a different approach to these projects and I couldn't have succeeded that much in those two if I didn't have some experience from this."

At the same time, the public servants involved in the MindLab case study recognised the expertise required to get to a successful result at the completion of the design process

[Public servant, MindLab]: "We need both. We are not as good as we want to be in this thinking. [...]. We would not have ended up with [this solution] without the MindLab thinking."

\section{Discussion}

\subsection{Design capability in public and social innovation}

In this study, design expertise could be recognised in the case studies through the way that the design networks framed the problem. In all cases this was mostly driven by the design teams from the social innovation agencies. Indicators of design expertise in framing could be recognised through 1) the principles that the agencies used to frame and 2) the 'non-linear' approach to framing and managing the process

\section{Framing principles}

The agencies used two main principles for problem framing-'opening up' the brief and applying systemic thinking. As discussed above this is in line with the 'systemic' nature of design as discussed by Nelson and Stolterman (2012).

\section{Non-linear approach to framing and managing the process}

The 'non-linear' approach to framing and managing of the design process included an evolution of the framing that was not 'planned' in advance. In all but one case study the frame evolved continuously through either reflecting on solutions (co-evolution of problem and solutions) or bringing in new human-centred research whenever it was deemed appropriate. This messy and intuitive nature of design is something that makes design hard to understand by novices.

\section{Levels of design expertise}

The framing principles and non-linear approach show a high level of design expertise. But what did we learn about the 'lower' levels of expertise? One case study is of particular interest here. This team showed design expertise in the initial framing of the problem, opening it up, and taking it to a systems level. However, parts of the process were so methodical and 'templated' that it did not allow the problem and solution to co-evolve. Rather, the problem was explored and framed before solutions were generated. This is in line with a more 'rule-based' approach, and seems to lack expertise with regard to managing a non-linear design process. However, the fact that this team did manage to reframe the broader problem does show higher level expertise than novices. This is in line with Lawson and Dorst (2009) who state that there are many elements to design expertise and that you can be more expert in some elements and less expert in others.

The anecdotal evidence of the learning outcomes of participants shows that many have changed their thinking around how to address problems, but that this is still rule-based. However, they did improve their expertise beyond 'everyday' or innate design expertise levels (Lawson \& Dorst, 2009; 
Manzini, 2015). This in-between level of design expertise needs to be explored further to be able to develop appropriate capability building programs.

Another question is who needs to have which level of expertise. A tentative answer could be that practitioners need high level expertise for complex challenges, and that people working in the public and social sector need at least enough expertise to recognise when a problem can be solved using 'beginner' expertise, and when they need to engage with expert designers. This shows that we will need to develop more specific indicators of design expertise in public and social innovation.

\subsection{Teaching design in public and social innovation}

The complex nature of the challenges that public and social innovation agencies aim to address requires a different approach to design. Burns, Cottam, Vanstone, and Winhall (2006) refer to this as 'transformation design', the expertise to address complex problems and to create fundamental change. It "seeks to leave behind not only the shape of new solutions, but the tools, skills and organisational capacity for ongoing change" (p.21). More than one decade later, we can see how innovation agencies are indeed focusing on this need to build design capability within organisations. However, we argue that the teaching and learning models for this capability building need further exploration in terms of the targeted learning outcomes in relation to levels of expertise, and the learning models in relation to these levels of expertise.

It is undisputed that design can only be learned by doing. The experiential learning model is therefore widely adopted in design curricula. An essential part of experiential learning is reflection on the experience (Moon, 2004), as visualized in the well-known learning cycle of Kolb (1984). In design curricula this is achieved through, for example, the 'studio-model' and the design critique. In design practice, ongoing reflection individually and as a team supports professional practitioners to keep developing themselves (Lawson \& Dorst, 2009).

The learning models described in the case studies do have experiential elements. This is in line with what Yee and White (2015) found with regard to capability building in design projects in the public and social sector, in which key stakeholders are often invited to apply 'tools' to go through a learning cycle of experiential learning, and in some cases explicit 'training' is offered. This would suffice for the 'rule-based' practices of a beginner designer. However, it comes nowhere near the years of education that traditional designers receive. Cross (2004) discusses the time that is required to obtain high level design expertise, and concludes from studies of expertise that it requires a minimum period of practice and sustained involvement. Referring to Ericsson (2001), who is an expert in the study of expertise, "superior expert performance is primarily acquired... many thousands of hours of deliberate practice and training are necessary to reach the highest levels of performance" (Cross 2004, p428).

This level of expertise is clearly far beyond what can realistically be achieved in any 'design capability building program'. For this level of expertise, public and social sector organisations need to hire or work with experts that have built up expertise through years of experience of designing within a social innovation context. At the same time, we need to acknowledge that this field of design and social innovation is young, and that continuous professional learning needs to be supported, as outlined by Nelson and Stolterman (2012, p228): "Designers as professionals need to have both training and learned experiences to develop the multiple forms of expertise needed to create desired changes in the complexity and uncertainty of today's world."

An interesting paradox in capability building is that addressing complex societal problems requires high-level design expertise, but to acquire this expertise, novice designers need experience in working in this context. The case studies that were focused on capability building in this study used the latter approach-working with novices in a real-world context which had less impact on the project outcomes in comparison to the other agencies that relied on high-level expertise. This suggests that organisations need to be aware that they need to balance getting outcomes for the project with getting learning outcomes for participants. A better articulation of design expertise and 
learning models could contribute to helping public and social sector organisations set a strategy with regard to building innovation capability.

\section{Conclusion}

The study described in this paper contributes to developing a better articulation of what design is and what it means in the context of public and social sector innovation, as well as to the development of strategies to increase design expertise in designing networks that are aimed at addressing complex societal problems. The study indicates that public and social sector innovation in the complex context requires high level design expertise. This type of expertise requires years of practice. Even though toolkits with step-by-step methods and templates are great for creating 'design literacy', these approaches are unlikely to get inexperienced people in a designing network beyond the novice level to 'design fluency'. Further research is required to better articulate what level of expertise is required for which type of role and situation in a public and social sector context, and how it should be taught.

Acknowledgements: We gratefully acknowledge the contribution of all the interviewees of the five case studies. We would also like to thank Sidse Ansbjerg Bordal for her assistance in conducting the case study with MindLab.

\section{References}

Bason, C., \& Schneider, A. (2014). Public Design in Global Perspective: Empirical Trends. In C. Bason (Ed.), Design for Policy (pp. 23-40). Surrey, England: Gower Publishing Limited.

Burns, C., Cottam, H., Vanstone, C., \& Winhall, J. (2006). Transformation Design. Retrieved from London, UK: http://www.designcouncil.org.uk/sites/default/files/asset/document/red-paper-transformationdesign.pdf

Cross, N. (2004). Expertise in design: an overview. Design Studies, 25(2004), 427-441.

Dorst, K. (2011). The core of 'design thinking' and its application. Design Studies, 32(6), 521-532.

Dorst, K. (2015). Frame Innovation; create new thinking by design. Cambridge, Massachusetts: The MIT Press.

Dorst, K., \& Cross, N. (2001). Creativity in the design process: co-evolution of problem-solution. Design Studies, 22(5), 425-437.

Ericsson, K. A. (2001). Attaining excellence through deliberate practice: insights from the study of expert performance. In M. Ferrari (Ed.), The pursuit of excellence through education. Hillsdale, NJ, USA: Erlbaum.

Kolb, D. A. (1984). Experiential learning: experience as the source of learning and development. Englewood Cliffs, NJ: Prentice Hall.

Lawson, B., \& Dorst, K. (2009). Design expertise: Elsevier Ltd.

Manzini, E. (2015). Design, When Everybody Designs - An Introduction to Design for Social Innovation. Cabridge, Massachusetts: The MIT Press.

Moon, J. A. (2004). A handbook of reflective and experiential learning: theory and practice. London and New York: RoutledgeFalmer.

Mulgan, G. (2014). Design in public and social innovation; What works and what could work better. Retrieved from http://www.nesta.org.uk/sites/default/files/design_in_public_and_social_innovation.pdf

Nelson, H. G., \& Stolterman, E. (2012). The design way - Intentional change in an unpredictable world (Second Edition ed.). Cambridge, Massachusetts: The MIT Press.

Schön, D. (1983). The Reflective Practitioner: How Professionals Think in Action. New York, NY: Basic Books, Inc.

Simon, H. A. (1996). The sciences of the artificial (3rd edition ed.). Cambridge, MA: The MIT Press.

Valkenburg, R., \& Dorst, K. (1998). The reflective practice in design teams. Design Studies, 7(2-3), 111-121.

van der Bijl-Brouwer, M., \& van der Voort, M. (2014). Establishing shared understanding of product use through collaboratively generating an explicit frame of reference. CoDesign, 10(3-4), 171-190.

van der Bijl-Brouwer, M., Kaldor, L., Watson, R., \& Hillen, V. (2015). Supporting the emerging practice of public sector design innovation. Paper presented at the IASDR2015 Interplay, Brisbane, Australia.

van der Bijl - Brouwer, M., \& Dorst, K. (2017). Advancing the Strategic Impact of Human-Centred Design. Design Studies, 53(2017), 1-23. 
Yee, J., \& White, H. (2015). The goldilocks conundrum: the 'just right' conditions for design to achieve impact in public and third sector projects. International Journal of Design, 10(1), 7-19.

Yin, R. K. (2009). Case Study Research, Design and Methods (Fourth ed.): SAGE Inc.

About the Authors:

Mieke van der Bijl-Brouwer is Senior Lecture at the Faculty of Transdisciplinary Innovation at the University of Technology Sydney. She is interested in the collaborative and creative practices, skills and mind sets that are required to address complex societal problems.

Bridget Malcolm is a Strategic Design Research Practitioner at the Design Innovation Research Centre at the University of Technology Sydney. She is passionate about supporting leaders to evolve their practice and address increasingly complex problems. Bridget holds a Master of Design (Research). 